\title{
Co-circulation of dengue, chikungunya, and Zika viruses and cross-protection
}

To the Editor:

We read the publication on "Co-circulation of dengue, chikungunya, and Zika viruses in Colombia from 2008 to 2018" with a great interest (1). Rico-Mendoza et al. concluded that "The decrease in the number of dengue cases after co-circulation of the three viruses could indicate possible cross-protection" (1). We would like to share ideas on this report. An interesting question is whether there is a cross-protection or not. Based on our setting in Indochina, a similar co-circulation of the three viruses presently exists but there has never been any decrease in number of dengue. In addition, there is no clear report showing that there is a cross-protection due to the three virus co-circulation. Priyamvada et al. mentioned that there might be a common host immune response among viruses due to viral structural similarity, but it is still no data regarding the immunoprotection (2). Based on a recent publication by Wen et al., it is observed that there might be a cross protection via CD8+ but Wen et al. mentioned that "passive transfer studies suggest that DENV-immune serum does not protect against ZIKV infection" (3). Based on the data by Rico-Mendoza et al., there is also a fluctuation of the number of the cases (such as between 2016 and 2018) (1). The fluctuation, increased and decreased rate, might be due to several factors including to the environmental factors that might stimulate or suppress the epidemic of the vector borne disease. Due to the worldwide concern on Zika virus, there might be some intensified prevention program against mosquito borne disease.

\section{Conflicts of interest. None declared}

Disclaimer. The author holds sole responsibility for the views expressed in the manuscript, which may not necessarily reflect the opinion or policy of the RPSP/PAJPH and/or PAHO.

\section{Beuy Joob}

Sanitation 1 Medical Academic Center, Bangkok, Thailand

\section{Viroj Wiwanitkit}

Department of Community Medicine, Dr DY Patil University, Pune, India

Suggested citation Joob B, Wiwanitkit V. Co-circulation of dengue, chikungunya, and Zika viruses and cross-protection. Rev Panam Salud Publica. 2019;43: e75. https://doi.org/10.26633/RPSP.2019.75

A reply to this letter is avaliable at: https://doi.org/10.26633 /RPSP.2019.77

\section{REFERENCES}

1. Rico-Mendoza A, Porras-Ramírez A, Chang A, Encinales L, Lynch R. Co-circulation of dengue, chikungunya, and Zika viruses in Colombia. Rev Panam Salud Publica. 2019; 43:e49. https://doi. org/10.26633/RPSP.2019.49

2. Priyamvada L, Hudson W, Ahmed R, Wrammert J. Humoral cross-reactivity between Zika and dengue viruses: implications for protection and pathology. Emerg Microbes Infect. 2017 May 10;6(5):e33. doi: 10.1038/emi.2017.42.

3. Wen J, Elong Ngono A, Regla-Nava JA, Kim K, Gorman MJ, Diamond MS, Shresta S. Dengue virus-reactive CD8+ T cells mediate cross-protection against subsequent $\mathrm{Zika}$ virus challenge. Nat Commun. 2017 Nov 13;8(1):1459. doi: 10.1038/s41467-017-01669-z. 